\title{
HEALTH MONITORING OF STRUCTURES USING STATISTICAL PATTERN RECOGNITION TECHNIQUES
}

\author{
Ahmed S. Noman ${ }^{1}$, Farah Deeba ${ }^{2}$, and Ashutosh Bagchi ${ }^{3}$ (M.ASCE) \\ Department of Building, Civil and Environmental Engineering \\ Concordia University, Montreal, Canada
}

\begin{abstract}
The primary objective of Structural Health Monitoring (SHM) is to determine whether a structure is performing as expected or there is any anomaly in its behavior as compared to the normal condition. It is also useful in detecting the existence, location and severity of damage. Vibration based damage detection methods are very frequently used in SHM. But due to complicated features of real life structures, there are uncertainties involved in the key input parameters (e.g. measured frequencies and mode shape data) which affect the performance of these methods. If vibration based methods are incorporated with semi-analytical method such as statistical pattern recognition techniques, better accuracy can result in structural health assessment. This paper explores the statistical pattern recognition techniques for damage detection and/or degradation in structures. A case study, the Portage Creek Bridge in Victoria, British Columbia has been used. The following two approaches of the statistical pattern recognition techniques have been used: statistical pattern comparison, and statistical model development. After filtering and normalizing the data; obtained from the SHM system installed in the bridge damage sensitive features have been extracted by Auto Regressive (AR) modeling of time series data. Both idle and excited states of the bridge are considered in this case. From the statistical analysis of the strain and acceleration data, it has been found that while the bridge is in a good condition, there is a small, but steady deterioration in its performance. The study also demonstrates the feasibility of the statistical pattern recognition techniques in assessing the structural condition of a practical structure.
\end{abstract}

Keywords: structural health monitoring, bridge, statistical pattern recognition, auto regressive modeling, feature extraction, damage detection

\footnotetext{
${ }^{1}$ Assistant Professor, World University of Bangladesh, Dhaka; Formerly Graduate Student, Department of Building, Civil and Environmental Engineering, Concordia University, Montreal, Canada.

${ }^{2}$ Structural Engineer (jr), SNC Lavalin, Montreal; Formerly Graduate Student, Department of Building, Civil and Environmental Engineering, Concordia University, Montreal, Canada.

3 Associate Professor, Department of Building, Civil and Environmental Engineering, Concordia University, Montreal, QC, H3G 1M8, Canada; Corresponding Author (abagchi@bcee.concordia.ca)
} 


\section{INTRODUCTION}

In general Structural Health Monitoring (SHM) is concerned with performance monitoring of structures using various sensors and devices to ascertain the strength of critical members of the structure and find the presence of any damage or anomaly. SHM is also intended to evaluate degradation rate and predict the remaining service life of a structure. An appropriate SHM system can help reduce the chance of catastrophic failure, maintenance cost and down time for rehabilitation. According to Mirza and Haider (2003) more than $40 \%$ of the bridges in service in Canada are over 30 years old. While many of them need minor repair and functional improvements, a significant number of these bridges are structurally deficient and they are in urgent need of rehabilitation or partial re-construction. Chase and Washer (1997) conducted a similar survey for the bridges in the USA and found that about 187,000 bridges representing more than $25 \%$ of all bridges were deficient at that time, and about 5,000 bridges were becoming deficient every year. The above estimate was an improvement over previous years because of increase in federal bridge funding for building and rehabilitation of bridges. A more current statistics puts the number of deficient bridges to about $12 \%$ of the total National and State bridges (RITA, 2007). Most of these bridges were built before 1970 and their health condition is yet to be determined by any instrumental and scientific approach. The reduction from $25 \%$ in 1997 to $12 \% 2007$ is perhaps due to the continued reconstruction and rehabilitation efforts as mentioned earlier.

In the context of structural safety, maintenance and rehabilitation purposes, the need for SHM has increased recently. Traditionally, visual inspection is utilized as the primary means of monitoring structural health condition. Due to the drawbacks of visual inspection other methods such as Non Destructive Testing/Evaluation (NDT/NDE) are being increasingly used. However, NDT/NDE techniques are available for only periodic testing and monitoring local defects. By remotely monitoring a structure continuously or periodically, SHM offers to complement the information on the structural condition provided by visual inspection and NDE techniques. Structural model-based methods, such as vibration-based damage detection techniques as commonly used in SHM, are very sensitive to the noise in the data from the sensors (Bagchi et al., 2010). Data driven techniques do not require a structural model, and they provide attractive alternatives to structural model-based techniques for damage detection. Statistical pattern recognition techniques provide opportunities for developing data-driven models for structural damage detection and condition assessment.

According to Sohn et al. (2000), sensors measuring strains and vibration of a structure produce signals that always respond to the change of environmental and operational conditions. Each group of signals can be considered as a pattern (a definable entity) that has some relation to the structural and ambient conditions. If the effect of ambient condition to the patterns is normalized, they should be nearly identical or close to one another for similar load or vibration effect as long as structural vibration properties remain un-altered. However, it can be assumed that the change in physical properties, mainly stiffness, should be reflected on the processed signal blocks or patterns. Farrar et al. $(1999,2001)$ have proposed generalized integrated approach for structural health monitoring by statistical pattern. 
Statistical pattern recognition is relatively new in SHM applications where the data from sensors are collected and processed to remove the environmental (eg. temperature) effects, and filtered or denoised. In this context, statistical pattern comparison, and statistical model development approaches have been utilized recently (e.g., Shon et al., 2001; Niar an Kirmidjian, 2006) for assessing the condition structural elements. The statistical algorithms available for diagnosis based on SHM data are: Outlier analysis, Auto regressive exogenous (ARX) model, Auto regression moving average (ARMA) (Noman et al., 2009). Outlier detection is used when data is available only for undamaged state of a structure. In the statistical pattern comparison approach, the damage detection algorithm attempts to identify damage states by observing significant change in features that cannot be explained by extrapolation of previously observed features when the structure was at the normal state. On the other hand, the statistical model development approach can detect trends in the data that is useful to predict when particular features fail to follow the established trends or become outliers. Statistical process control techniques can be employed to identify trends using outlier analysis. If a structure is damaged, most values of extracted features should fall outside some threshold value determined by a specific algorithm. The main objective of this article is to study the application of data-driven techniques and develop methodologies utilizing statistical pattern recognition schemes such as, statistical pattern comparison and statistical model development approaches for interpreting SHM data including damage detection and structural condition assessment.

\section{DAMAGE ASSESSMENT BY STATISTICAL METHODS}

Time series analysis techniques are often utilized to extract the damage sensitive features of the vibration and strains data. Mathematical modeling of time series data is covered in relevant textbooks (e.g., Montgomery et al 2008). Statistical pattern comparison and model development are commonly used techniques for statistical pattern recognition, which are used for evaluating the changes in time series patterns and features. They are briefly discussed below in the context of structural condition assessment and damage detection.

\section{Statistical Pattern Comparison Approach}

The basic concept of this approach can be found in Sohn et al., (2001). It is logical to assume that the patterns in data in same state of condition, either steady or agitated state of a structure, taken at various points of time, will not vary much if the structure does not change significantly. Conversely, if the structure has undergone a significant change, it should reflect in the patterns of both states of condition.

In order to observe the variation in a structure's response by studying the patterns of signals from the sensors or data blocks, it is necessary to nominate a certain block as reference data block with which patterns of the other data series or blocks are compared. Usually, the reference data blocks for a particular condition are taken from an earlier time of the observation of the structure and other data blocks are called test blocks. The time series model such as the Auto Regressive (AR) model as used in this study, particularly developed for reference block is defined as reference model. As a structure undergoes gradual changes due to degradation, the data pattern changes accordingly. Therefore, the pattern of other data blocks deviate from that of the reference block. Thus, if we fit the reference model to the test blocks the "residual errors" should 
reflect the extent of variation of the signals. It is expected that if a structure undergoes a significant changes, residual error as compared to the reference model will be significantly high.

After calculating all coefficients of a time series model and fitting it to the data it is possible to get the residuals for all points. An average residual can be defined as, $\varepsilon=($ Residual SS $) / \mathrm{N}$, where, SS is the sum of squares of residuals of the model with respect to the actual data, and $\mathrm{N}$ is the observation number. This value $\varepsilon$ is the key parameter that can be used to see how good a reference model fits to the pattern of test data blocks. A degree of match or closeness between $r$ the reference model and a test block as defined by $R=\varepsilon_{t} / \varepsilon_{r}$ is called residual error index. Here, $t$ and $r$ suffices mean the test and reference blocks, respectively. If the value of $R$ shows a clear increasing trend over long time, it can be said that the structure is degrading.

\section{Statistical Model Development Approach}

Statistical model can be utilized to analyze the distribution of extracted features to determine the damage state of a structure. As there is no damaged case known for the bridge in the present study, unsupervised learning technique has been used for developing and training a statistical model. Here control chart analysis, a commonly used Statistical Process Control technique for Outlier Analysis, has been used. It is applied to the calculated and selected damage sensitive features. When a structure undergoes damage or deterioration, the mean and/or variance of the extracted features should change accordingly (Nair and Kirmidjian, 2006).

Extraction of statistical features in a time series data block corresponding to a sensor signal is an important step in statistical model development. All data are analyzed with AR process. The variation of AR process is mainly dependent on AR coefficients $\emptyset_{x j}$. Hence, $\emptyset_{x j}$ is considered as structural degradation feature or damage sensitive feature. For the calculation of the AR coefficients, Yule-Walker methods have been applied (Brockwell and Davis, 2002). Since AR process is zero mean method, the data blocks are mean corrected (ie, the mean value is subtracted from the series).

\section{DESCRIPTION OF THE MONITORED STRUCTURE}

The approach of damage detection methodologies developed herein has been demonstrated using a case study example, namely the Portage Creek Bridge (Figure 1), located in Victoria, British Columbia (BC) in Canada. The information on the sensing system can be found in Huffman et al (2006). The Portage Creek Bridge is a $124 \mathrm{~m}$ long, three-span structure with a reinforced concrete deck supported on two reinforced concrete piers, and abutments on H piles. The bridge was designed prior to the introduction of current bridge seismic design codes and construction practices. Therefore, it was not designed to resist the earthquake forces as required by recent standards. Later seismic assessment performed on the piers as reported in Mufti et al. (2004) showed that strength of the columns of Pier-2 were found to be insufficient according to the seismic provisions of bridge design standards at that time (e.g., CHBDC, 1988; CHBDC, 2000; FHWA, 1996). As the bridge is classified as a Municipal Disaster Route bridge, the BC Minitry of Transportation decided to retrofit the bridge pier to prevent collapse during a design seismic event, with a return period of 475 years. The innovative solution of Fiber Reinforced Polymer (FRP) wraps was 
chosen to strengthen the short columns to conform to the seismic provisions of the Canadian Highway Bridge Design Code (CHBDC, 1988; CHBDC, 2000) and AASHTO (1996). The strengthened columns of the bridge pier were instrumented by ISIS (Intelligent Sensing for Innovative Structures) Canada, a federally funded Network of Centers of Excellence, to assess the performance of FRP strengthening system and the use of Fiber Optic Sensors (FOS). A Structural Health Monitoring (SHM) was installed on the columns for that purpose. The strengthened columns were instrumented with eight bi-directional rosette type strain gauges and four long gauge fiber optic sensors attached to the outer layer of the wraps (Figure 2). In addition, two 3-D Crossbow accelerometers are installed on the pier cap above the columns and a traffic web-cam mounted above the deck at the pier location (Bagchi et al., 2007).

\section{DATA ANALYSIS METHODOLOGIES}

\section{Data collection}

For the present study, a set of data covering a period of three years between April, 2003 and August, 2006 available from ISIS Canada research network has been used. However there are some time segments for which data are not available. These off-time segments are distributed through the whole period of the study. Of eight strain gauges on each column, one is possibly damaged (SG8). Thirty strain signals from fifteen 2D strain gauges, six accelerometer readings from two 3D-accelerometers and one temperature data series are available. The original sampling rate is $32 \mathrm{~Hz}$ with the Nyquist frequency of $16 \mathrm{~Hz}$, which is deemed adequate, given that the fundamental frequency of the structure is about $2 \mathrm{~Hz}$ and first five modes contribute more than $95 \%$ mass. The fifth mode frequency is below $4 \mathrm{~Hz}$ for which a sampling rate of 32 $\mathrm{Hz}$ is adequate.

In the beginning, the data sets were rendered graphically for various sampling rates and time segments to examine the overall nature and trend of the data. For example, the data series shown in Figure 3 for Strain Gauge 1 (according to Figure 2) or SG1 in short, was sampled at $1 \mathrm{~Hz}$ for a period of 8 hours 20 minutes in April 2006. Careful inspection shows that the strain is oscillatory in time. There are also some random vertical straight lines. It seems that those random lines were resulted from some sudden impacts. Further analysis revealed that the oscillation is mostly due to the effect of temperature changes, and the random vertical lines are the results of live loads, possibly heavy vehicles.

The rightmost and longest vertical straight line in Figure 3a (indicated by Line A) now looks like a spike. If the sampling rate is increased to $32 \mathrm{~Hz}$ for the data around the spike at $\mathrm{A}$, it shows clearly in Figure $3 b$ that the change of strain over a short period of time is the result of a gradually changing load, not an impact as appeared in Figure $3 \mathrm{a}$. This is the characteristic of a load applied on a pier by a vehicle moving on a bridge. As shown in Figure 3(b), the interval between Points $\mathrm{B}$ and $\mathrm{C}$ indicates the duration of load experienced by the pier while a truck passes over it. In this case, the duration is estimated to be $5.5 \mathrm{~s}$.

Based on the observations similar to the one mentioned above, it is apparent that in order to study the structural behavior of the bridge, it is necessary to analyze it under the following two conditions: (1) steady state condition where only small oscillations are observed; and 2) the agitated or live loaded condition in addition to small oscillations. 


\section{Data block Sampling and Analysis Schemes}

The data or in other words signal blocks are collected for 4 types of analysis: (a) steady state strain, (b) live load strain, (c) Accelerometer reading under live load, and (d) temperature effect on strain

How the data was collected for all cases is briefly described below.

1) Steady state strain: Figure 4(a) shows typical steady state condition plotting. It represents the condition when there is no live load such as a vehicle on the bridge. Steady state strain from SG 1 was taken for the study in this case. For steady state strain the data blocks are taken $8 \mathrm{~s}$ long (256 points at $32 \mathrm{~Hz}$ sampling rate). A total number 27 data blocks covering the monitoring period are considered here.

2) Live load strain: Figure 4(b) shows a typical acceleration time history at live loaded condition. A typical strain history at such condition is similar to the one shown in Figure 4(b). The cases where the data values exceed those at steady state conditions are considered to represent the live load events. Correspondingly nine random data blocks were taken that include heavy vehicle loads for each of 7 strain readings of column 1 and 8 of column 2 . Each block has sampling frequency $32 \mathrm{~Hz}$ and duration of 8 seconds. These strain gauges (SG) are: SG1 (horizontal direction of strain gauge 1 in column 1 as shown in Figure 2), SG2, SG3, SG5, SG6, SG17, SG18, SG19, SG20, SG21, and SG22. The length of each block is chosen to be $8 \mathrm{~s}$ as a truck typically does not take more than that time to pass over the pier (e.g. in the case shown in Figure 3b).

Analysis of these signal blocks will not only provide information on the structural behavior of the bridge over time under live loads, but also determine if all the gauges are working properly and find out the faulty one, if there is any. The change of behavioral patterns is expected to be similar for all gauges if they are all functioning properly. The magnitude and signs may vary among the data series but relative values in the test blocks as compared to the reference blocks of a particular strain channel should not differ significantly from the corresponding values of strains from other channels, particularly those in the same orientation. The data from the accelerometers and thermocouples are analyzed in the following ways.

1) Accelerometer reading under live load: The data blocks of accelerometer were taken at the same time, sampling frequency and duration as the blocks of live load condition. An example of time series is shown in Figure 4(b).

2) Temperature effect on strain: The stain values and temperature at time 00:00 of the first day of each month is taken for the analysis. The care was taken that data thereby obtained is of strictly steady state conditions. Then linear regression is applied on the data of several months to determine the temperature strain relation over those months. 


\section{RESULTS OF THE CASE STUDY}

\section{Pattern Comparison}

To apply this method several sample data blocks for selected strains and accelerometer readings have been used. The first block of each series of a particular strain or accelerometer is considered to be the reference block and the rest of the data blocks from the set are called test data blocks. Some typical results of the analysis are presented through Figures 5 through 7.

The Residual Error Index value indicates the closeness with the AR model, which can also be a good indicator of structural condition over time. It is logical that $R$-values of a particular strain acceleration signal should be steady and stay close to the base line of 1 over time. Upwards trend or deviation from the horizontal line at $R$-value of 1 over time indicates degradation. Figure 5(a) shows that $R$-values for 27 blocks (monthly) of SG1 at steady state do not have any particular trend. Similar characteristic is observed for the live loaded conditions. Figure 5(b) shows the Rvalues for 55 successive occurrences of live loads occurring successively. On the other hand, Figure 6(a) and (b) show the R-value for 31 blocks ( 1 per day), and 39 blocks (1 per 5 days), respectively, of live loaded condition of SG1. There is a noticeable peak value corresponding to the block sequence 30 in Figure 5(b). There could be two possible reasons for this

a) The vehicle passing over the column 1 was such that it produced higher stress on the location of strain SG1 and its pattern deviated from the normal state.

b) There was another vehicle nearby and the combined effect produced an irregular pattern.

The $R$-values of 9 blocks of 7 stains in column 1 and 8 blocks of 8 stains in column 2 at 1 block per 4 month interval over the entire period of monitoring as considered here have been observed. All strain gauge data have been analyzed at the same time segments. From the analysis it is clear that almost all the strain signals produced similar patterns with R-values not deviating from each other significantly. This also indicates that all strain gauges are working properly. Figure 7 shows the results of the analysis for Accelerometer A1 which also do not indicate any visible trend. The results of the pattern comparison method show that there is no indication that the structure is damaged or undergoing strength degradation.

\section{Statistical Model Development}

The signal blocks of data from strain gauges SG1, SG2 and SG3, and Accelerometer A1 have been used for creating the pool of features, which are AR coefficients. Care has been taken not to mix up strain with acceleration data for feature extraction; they are analyzed and presented separately. For the process control analysis according to Nair and Kiremidjian (2006), the first three AR coefficients give the most robust damage indication. So the first three coefficients of the AR analysis of strain blocks are taken. The mean and standard deviation of the first quarter of the arranged features are taken as reference. Here X-bar control charts are employed to monitor the changes of the selected feature over time. Subgroup of 4 features is considered here. The subgroup size is taken as 4 according to the suggestion of Montgomery (1997). The results for three AR coefficients of strain readings from SG1 and SG2 are shown through Figures 8 and 9. 
Examining the control charts in Figures 8 and 9, only 1 outlier of total $132(0.75 \%)$ subgroups of the first 3 AR coefficients of data from SG1 is detected and no outlier is found for SG2. However a slight downward tendency of the features is noticeable. Of a total of 124 subgroups of the first 3 AR coefficients for each of $x$ and $y$ channels of Accelerometer A1, only one $(0.81 \%)$ and zero outlier, respectively have been detected. Three outliers of total $108(2.78 \%)$ subgroups of the first 3 AR coefficients of for $z$ channel of Accelerometer A1 have been found.

Sohn et al., (2000) conducted a laboratory test on a set of concrete columns. At a very mild damaged state, statistical modeling showed $6.25 \%$ outliers, while at a significant damage it showed $29.17 \%$ outliers of all the subgroups. It is difficult to make a judgment based on a single study like this and extend it to bridge pier in the current study. However, it can be safely assumed that a small percentage of outliers $(<3 \%)$ is indicative of virtually no change the behaviour of a system. As the percentage of outliers in strain and acceleration data from the bridge columns in the present study is quite low, they are assumed to sustain no damage. This is of course, expected for a bridge of this age. However the tendency of the features getting closer to the limits towards the end of the monitoring period under consideration indicates that the structure is undergoing small degree degradation towards the end of that period.

It was observed from the data blocks that for each sensor there was an increment in the average strain readings in each year as compared to the than previous year. Here only the data blocks for SG2 are discussed with respect to a finite element model (FEM) and AR coefficients. The average strain values of SG2 for different summer periods in 2003, 2004 and 2006 are found to be $401 \mu \varepsilon, 521 \mu \varepsilon$, and $651 \mu \varepsilon$, respectively.

A two-dimensional Finite Element (FE) model as shown in Figure 10 has been developed to perform a simple static analysis to show the structural changes over time. In this model, the weight of half of the deck system and pier self weight has been applied as uniformly distributed load on the pier which is estimated to be $370 \mathrm{kN} / \mathrm{m}$, and concentrated loads due to self wt of the columns $1300 \mathrm{kN}$. For vehicle loading CL1-W Truck loading as defined is the Canadian Highway Bridge Design Code (CHBDC, 2006) has been applied as two concentrated load on either side of the axle and this loading has been applied on both lanes. The wheel load is 312.5 $\mathrm{KN}$ per wheel. But the load is increased to $500 \mathrm{kN}$ applying an impact factor 1.6 to take the dynamic impact into consideration. An estimated lateral load of $2000 \mathrm{kN}$ was applied to represent the EQ and/or wind load using the provisions of CHBDC. In the FE analysis and the analysis of the monitored data, it assumed here that there is no change in traffic load or pattern during the monitoring period considered here, and the measured strain data are filtered properly to remove the environmental effects on strain, Considering the time window for a passing vehicle, the increase in strain due to vehicle load can be considered to be free from environmental effects such as, temperature change.

In the FE model the loading condition and the structural stiffness have been adjusted to obtain a strain value of 400 microstrain which is the average strain value for summer 2003. It should be noted that the strain gauges installed on the column would not capture the strain due to the dead load as the gauges are installed and calibrated when the bridge superstructure already existed. This has been considered in the adjustment of the model by removing the initial strain due to dead load from the strain values obtained from the FE analysis. Assuming no increment in traffic 
for the years and taking the temperature corrections into considerations; the stiffness of the structures has been updated to correspond with the strains for the subsequent years. The model adjustment yields is a gradual decrease in stiffness of 20 to $30 \%$ to reflect the strain levels of $521 \mu \varepsilon$ in Summer 2004, and $651 \mu \varepsilon$ in Summer 2006, respectively. While the strain component due to environmental effects is difficult to properly filter from the data, qualitatively the reduction in stiffness indicates a gradual degradation of the bridge.

The first three AR coefficients are plotted for the data blocks of SG2 (Figure 9). The curves are showing a slight downward tendency, which is indicative of a reduction of stiffness as found with the FEM model correlation. In reality, this stiffness degradation is expected to be quite low in the initial years after the rehabilitation of the bridge.

\section{Temperature effect on Strains}

Temperature has a significant effect on the values of strains. Data blocks taken at different temperature with similar working conditions should show different values. Auto Regressive Process as applied in the previous section to analyze blocks of time series data is a zero mean process. Occurrence of such data in real life condition is very rare. By removing the mean from original values not only normalizes the data but also reduces the sample mean to zero. The temperature is almost constant for a time window 8 seconds for data blocks that are considered in time series analysis in this work. Usually temperature component is automatically removed by the removal of the mean from all observations (for a small time window), and the transformed values represent mostly the structural response. However, for other type of analytical processes on the strain data where zero mean process or any kind of normalization is not applied, temperature correction is needed to be applied explicitly to get the actual values of structural components of data.

To evaluate the effect of temperature on strain, Strain SG1 is selected. Figure 11(a) shows a typical strain history for SG1 at 1 second interval for a period 8 hours and 20 minutes starting at midnight in a March day in 2006. As discussed earlier, the big spikes in the graph are due to the effect of live loads from heavy vehicles passing over the pier to which the corresponding gauge is attached. The continuous small oscillations represent the steady state. The general upward trend of the graph towards the end is accounted for temperature effect.

Figure 11(b) shows the relation between strain and temperature considering twenty seven monthly readings of temperature and strain at Column 1 taken at time 0:0:0 on the first available day of each month. Linear relationships have been calculated by considering 1) all 27; 2) the first $10 ; 3)$ The next 10; and 4) the last 7 monthly readings. Because of space limitation, only the first two cases are shown here (Figures 11(a) and 11(b)). It should be noted that every strain gauge has its unique temperature-strain relationship. Though a liner relationship is ideally expected between temperature and strain, Figures $11 \mathrm{a}$ and $11 \mathrm{~b}$ show that linear regression does not always represent the accurate trend of the data. The linear relation between the strain data and temperature is most likely altered due to the presence of significant live loads. 


\section{DISCUSSION AND CONCLUSIONS}

Portage Creek Bridge (Victoria, British Columbia) is one of the disaster route bridges in British Columbia. In this case study, Statistical Modeling, and Pattern Comparison techniques have been utilized for developing a methodology for structural damage detection and condition assessment. One of the unique advantages of Statistical Pattern recognition techniques is that the sensor data need not be completely noise free. But for other procedures, for example: Vibration Based Damage Detection (VBDD), it is necessary that the filtered data is noise-free or they have very low level of noise (Humar et al., 2006). The important observations from the study are summarized below.

- The AR process has been applied here from the derived data blocks of strain measurements to extract the AR coefficients which are then statistically modeled for damage classification by X-bars. From the X-bars of strain and vibration data, percentages of outliers are found to be quite small which indicates that there is no damage in the structure or prominent structural degradation. However, a few cases suggest that the structure may be getting slightly degraded towards the end of the period considered, though it is still adequately safe.

- As an alternative approach to pattern comparison, statistical modeling and comparison of the reference models with blocks have been performed to determine the change in data pattern. Computed residuals as represented in $R$-values that represent the degree of closeness to the reference models do not show any deviation or discrepancies to indicate any damage in the structure. The data patterns also indicate that the sensors are functioning properly.

- Temperature has a significant effect on the values of strains. The strain data generally shows a linear relationship with temperature as expected. No linearity between strain data and temperature is indicative of significant live loads on the structure.

\section{ACKNOWLEDGEMENT}

The authors would like to thank Dr. Aftab A. Mufti, President of ISIS Canada Research Network, University of Manitoba, for making the SHM data and documentations for the bridge available for the study. The financial support of the Québec funding agency on Natural Sciences and Technology (FQRNT) is also gratefully acknowledged. 


\section{REFERENCES}

AASHTO, 1996, "Standard Specifications for Highway Bridges", Division 1-A, Seismic Design, Sixteenth Edition, American Association of State Highway and Transportation Officials 1996.

Bagchi, A., Humar, J., Xu, H, and Noman, A. 2010, "Model-Based Damage Identification in a Continuous Bridge using Vibration Data", ASCE $J$ of Performance of Constructed Facilities, 24(2): 148-158.

Bagchi, A., Huffman, S. and Mufti, A. A., 2007, "Seismic strengthening and structural health monitoring of Portage Creek Bridge", $9^{\text {th }}$ Canadian Conference on Earthquake Engineering, Ottawa, Canada, June 26-29.

Brockwell, P.J. and Davis, R.A., 2002, "Introduction to Time Series and Forecasting", SpringerVerlag, New York, $2^{\text {nd }}$ Ed., ISBN 978-0-387-95351-9.

Chase S.B., Washer G. (1997) Non-Destructive Evaluation for Bridge Management in the Next Century. Public road, 61 (1), http://www.tfhrc.gov/pubrds/july97/ndejuly.htm (last accessed on Dec 6, 2011).

CHBDC, 2000, Canadian Highway Bridge Design Code - CAN/CSA S6-00, Canadian Standards Association, Mississauga, Ontario.

CHBDC, 1988, Canadian Highway Bridge Design Code - CAN/CSA S6-88, Canadian Standards Association, Mississauga, Ontario.

Farrar, A. R., Sohn, H, Fugate, M. L., Czarnecki, J. J., 2001, "Integrated structural health monitoring", SPIE's 8th Annual International Symposium on Smart Structures and Materials, Newport Beach, CA, March 4-8.

Farrar, C. R., Duffey, T. A., Doebling, S. W., and Nix D. A., 1999; A Statistical Pattern Recognition Paradigm for Vibration-Based Structural Health Monitoring, the $2^{\text {nd }}$ International Workshop on Structural Health Monitoring Stanford, CA Sept 8-10.

FHWA, 1995, "Seismic Retrofitting Manual for Highway Bridges", Federal Highway Administration (FHWA), U.S. Department of Transportation.

Fugate, M. L., Sohn, H., and Farrar, C. R., 2001, "Vibration-Based Damage Detection using Statistical Process Control", accepted for publication of Mechanical Systems and Signal Processing, Academic Press, London, UK

Huffman S., Bagchi, A., Mufti, A., Neale, K., Sargent, D., and Rivera, E., 2006, “GFRP Seismic strengthening and structural health monitoring of Portage Creek Bridge Concrete Colums", The Arabian Journal for Science and Engineering, Volume 31, Number 1C.

Humar, J., Bagchi, A. and Xu, H. 2006, "Performance of Vibration-based Technique for Identification of structure Damage", Structural Health Monitoring - An International Journal, 5: 215-241.

Mirza, Saeed M. and Haider, Murtaza. "The State of Infrastructure in Canada: Implications for Infrastructure Planning and Policy", Infrastructure Canada, 2003

Montgomery, D. C., 1997, Introduction to Statistical Quality Control, John Wiley \& Sons Inc, New York, NY.

Montgomery D. C., Jennings C. L., and Kulahci M., 2008, "Introduction to Time Series Analysis and Forecasting", John Wiley \& Sons Inc, New York, NY.

Mufti, A., Neale, K., Huffman S., Sargent, D., and Bagchi, A., 2004, "GFRP Seismic strengthening and structural health monitoring of Portage Creek Bridge Concrete 
Colums", $13^{\text {th }}$ World Conference on Earthquake Engineering, Vancouver, Canada, Paper No 3237.

Nair, K., K., and Kiremidjian A., S., 2006, "A comparison of local damage detection algorithms based on statistical processing of vibration based measurements", Structural Health Monitoring and Intelligent Infrastructure - Edited by Qu, Li \& Duan, Taylor \& Francis Group, London.

Noman, A.S., Deeba, F. and Bagchi, A., 2009, "Vibration-based methods and statistical pattern recognition techniques in structural health monitoring", International Workshop on Smart Materials and Structures (CANSMART), Oct 22-24, Montreal, Canada.

RITA, 2010, Research and Innovative Technology Administration, U.S. Department of Transportation (US DOT), 1200 New Jersey Avenue, SE, Washington, DC, http://www.bts.gov/publications/national transportation_statistics/html/table_01 27.html (accessed, October, 2011).

Sohn, H., Czarneck, J. J., and Farrar, C. R., 2000, "Structural Health Monitoring using Statistical Process Control”, Journal of Structural Engineering, ASCE, 126(11):1356-1363.

Sohn, H., Farrar, C. R., Hunter N. F., and Worden, K., 2001, "Structural Health Monitoring Using Statistical Pattern Recognition Techniques", ASME Journal of Dynamics Systems, Measurements and Control, 123(4): 706-711. 


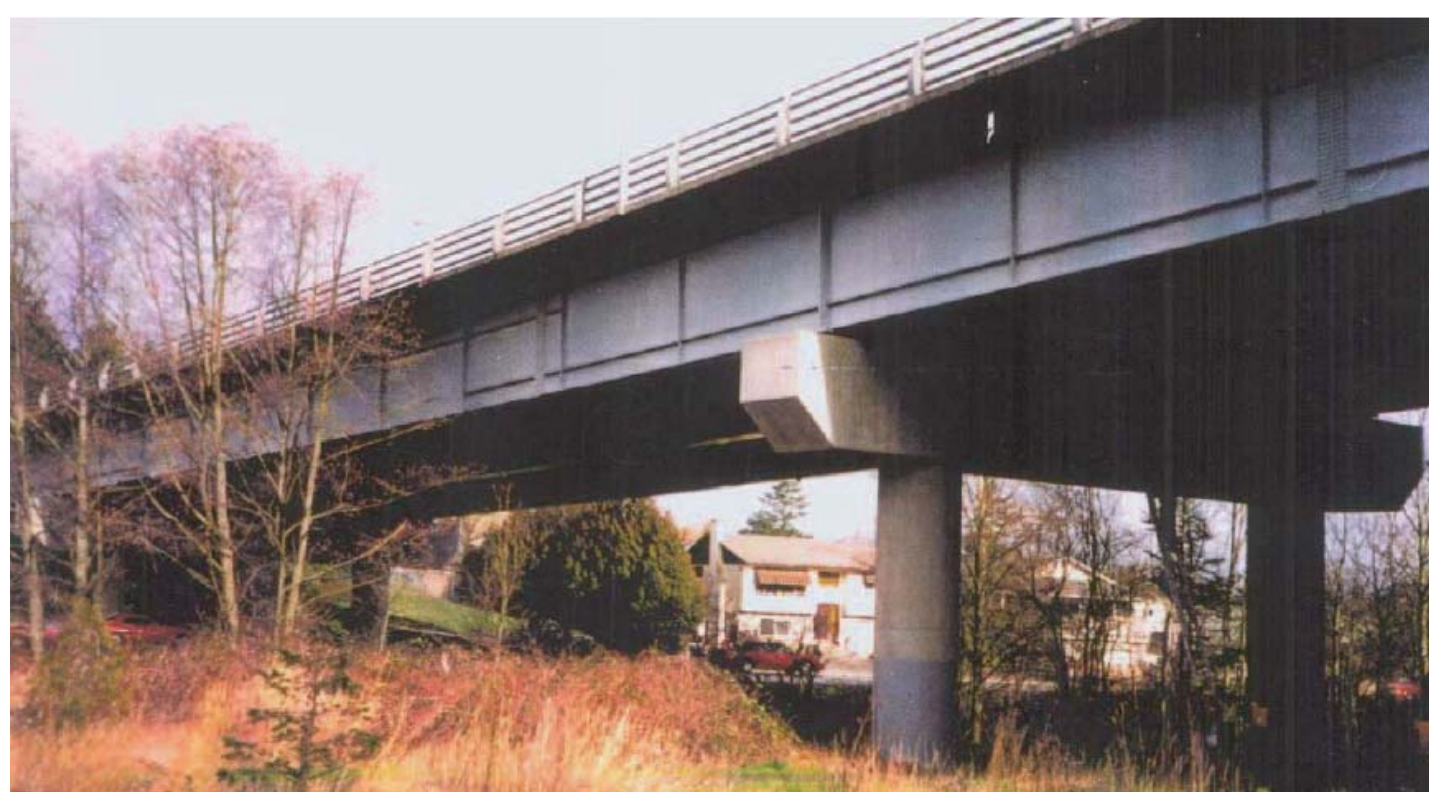

Figure 1: Portage Creek Bridge, Victoria, British Columbia, Canada

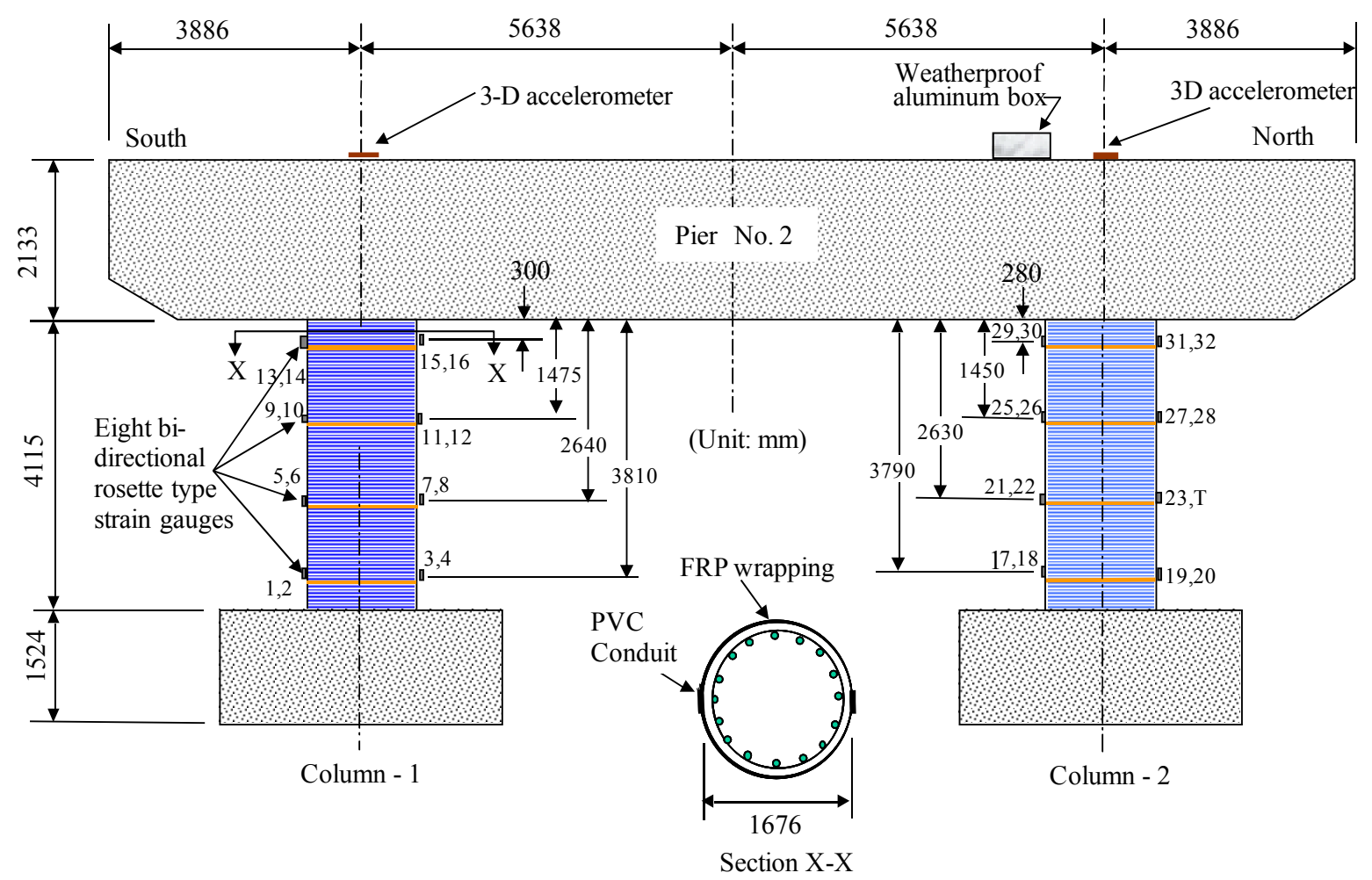

Figure 2: Elevation of Pier 2 (short columns) with sensor locations 


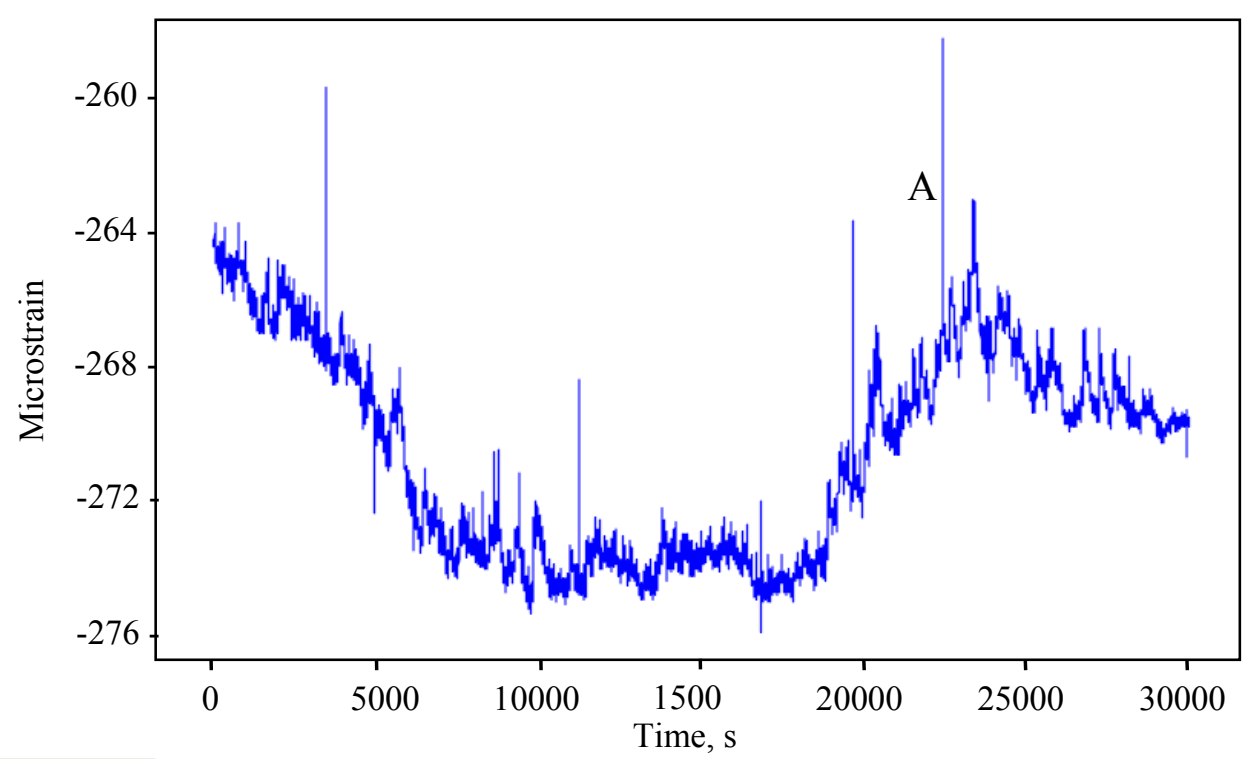

(a)

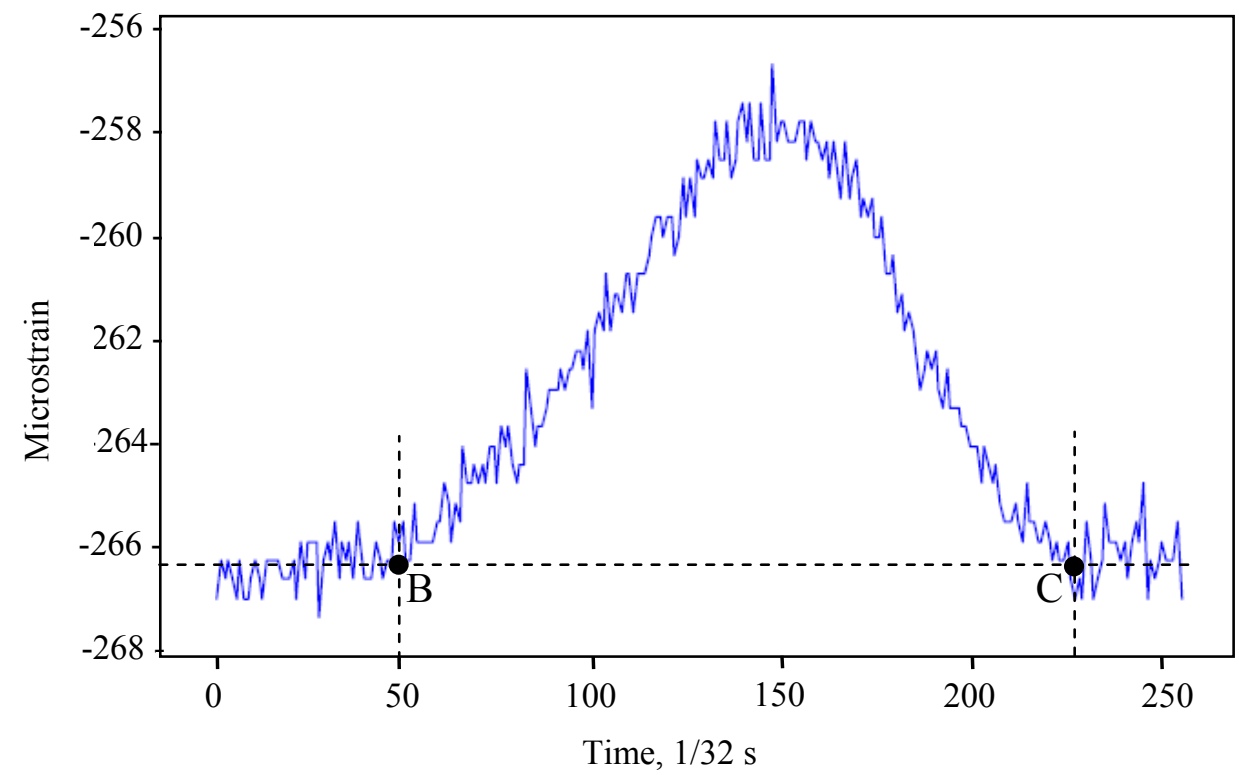

(b)

Figure 3: Typical time series' of strain from Strain Gauge 1 (SG1): (a) sampled at $1 \mathrm{~Hz}$; (b) under vehicle load, sampled at $32 \mathrm{~Hz}$ 


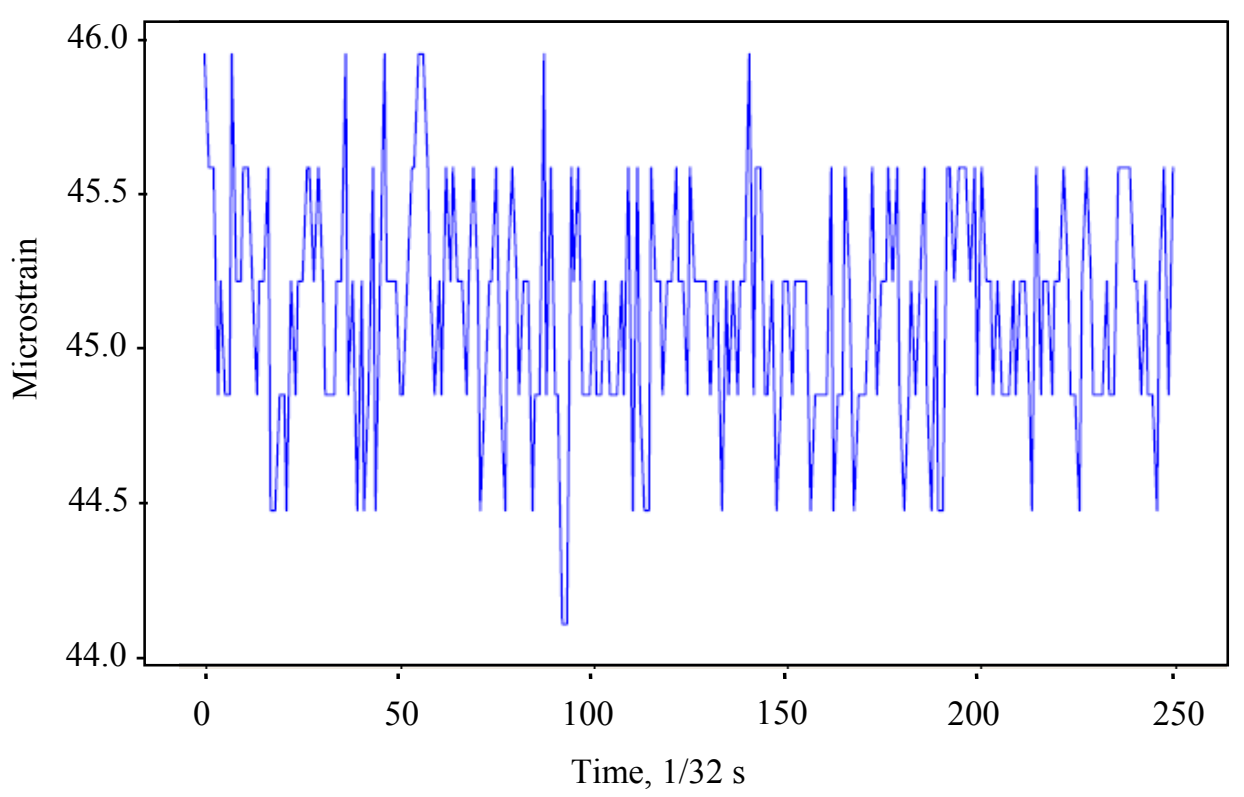

(a)

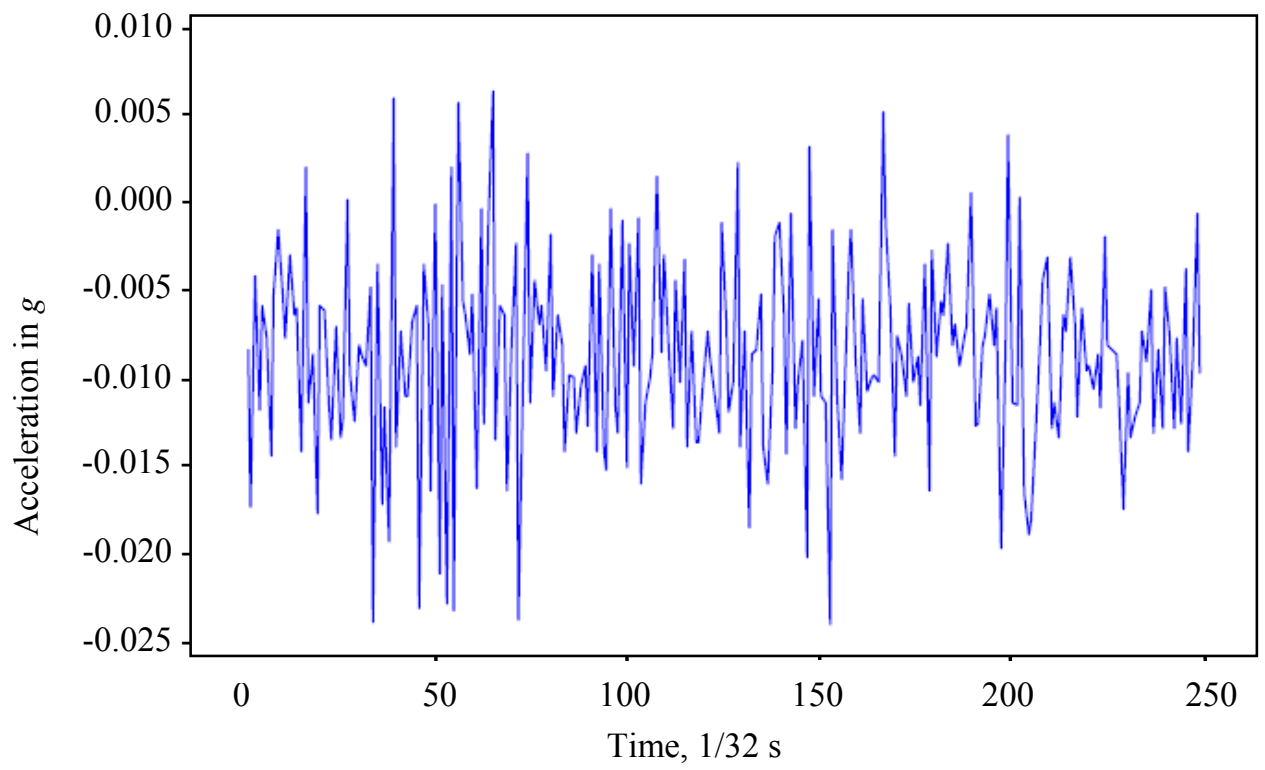

(b)

Figure 4: Typical signals from sensors at steady state: (a) strain signal from SG1; (b) Accelerometer signal from A1 in x direction 


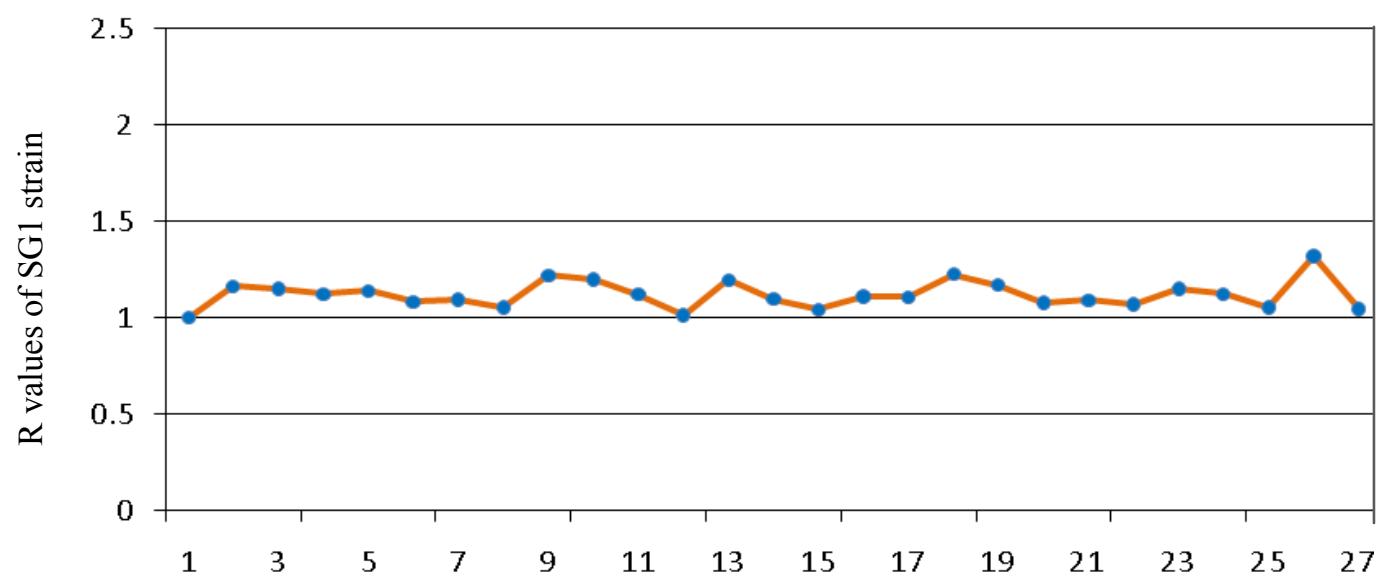

Sequence of data blocks

(a)

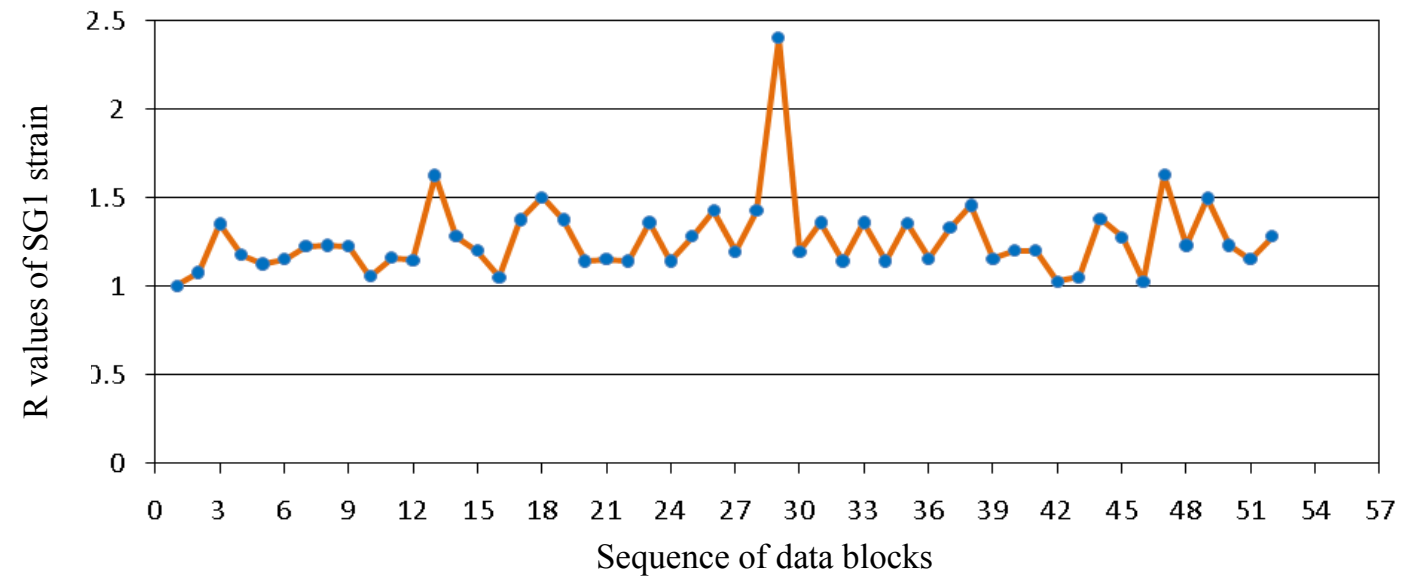

(b)

Figure 5: R-values of Strain from SG1: (a) for 27 data blocks at Steady State Condition; (b) for 55 data blocks in live loaded occurrences on continuous scanning 


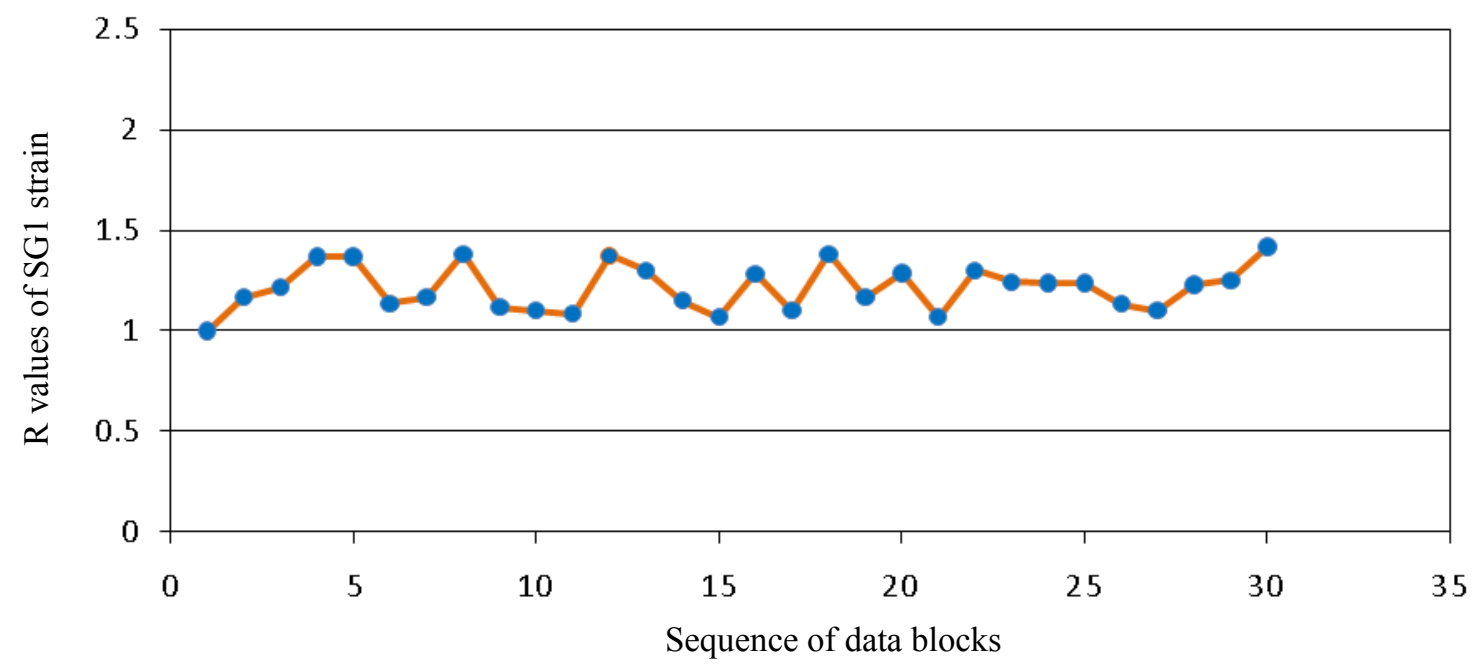

(a)

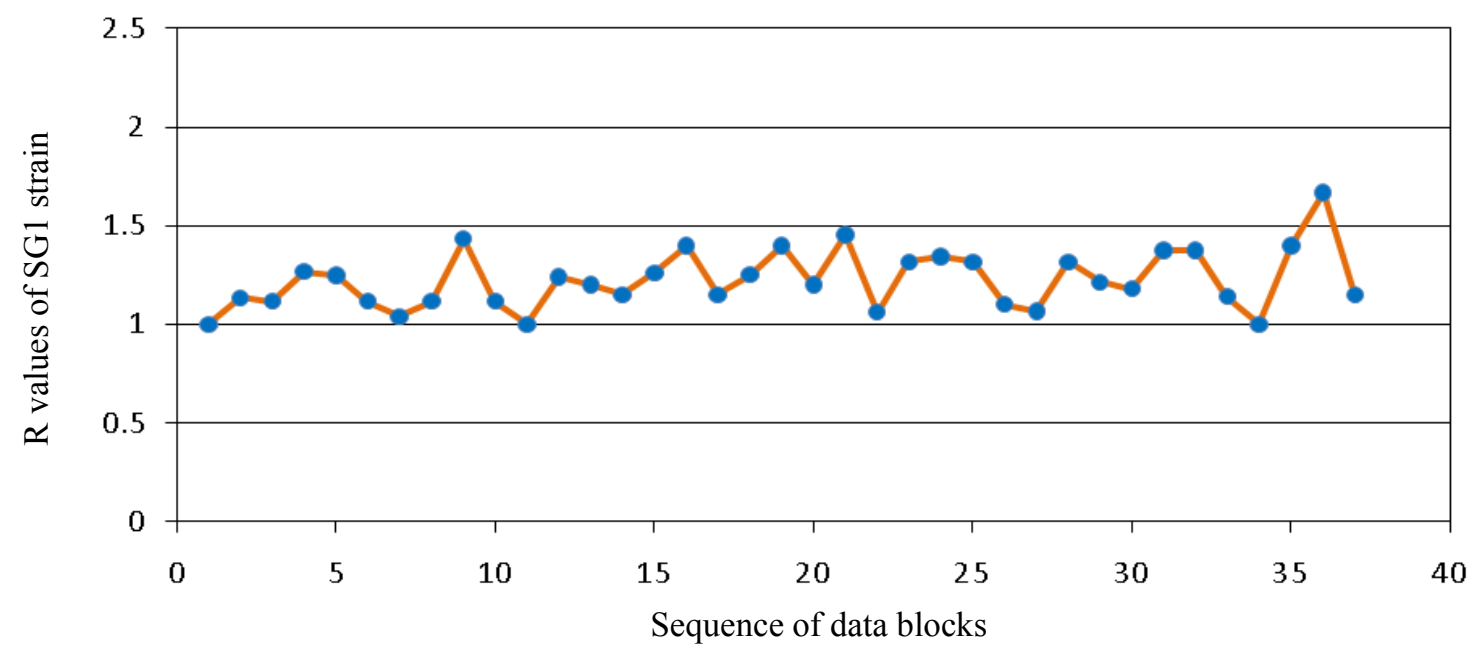

(b)

Figure 6: R-values of strain from SG1 in live loaded conditions: (a) for 31 cases at 1 data block per day; (b) for 39 live cases at 5 days interval 


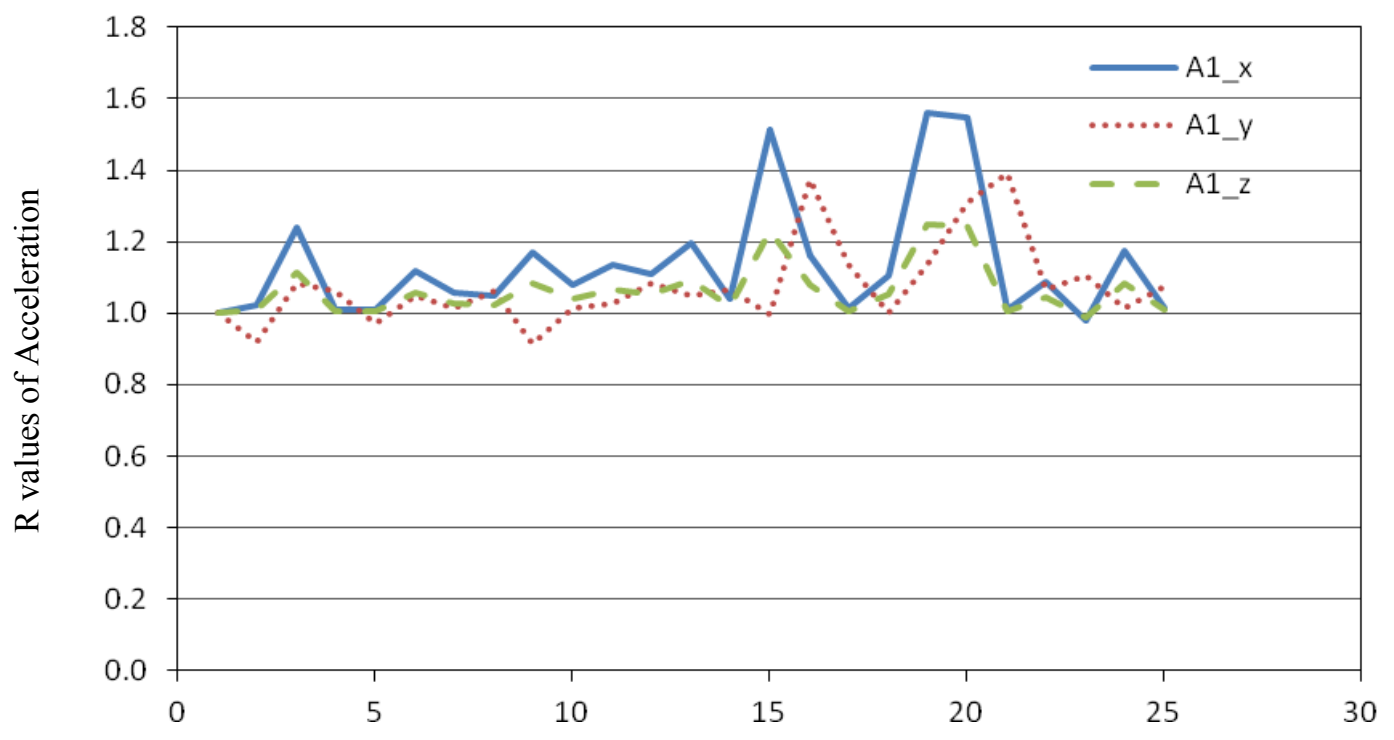

Sequence of data blocks

(a)

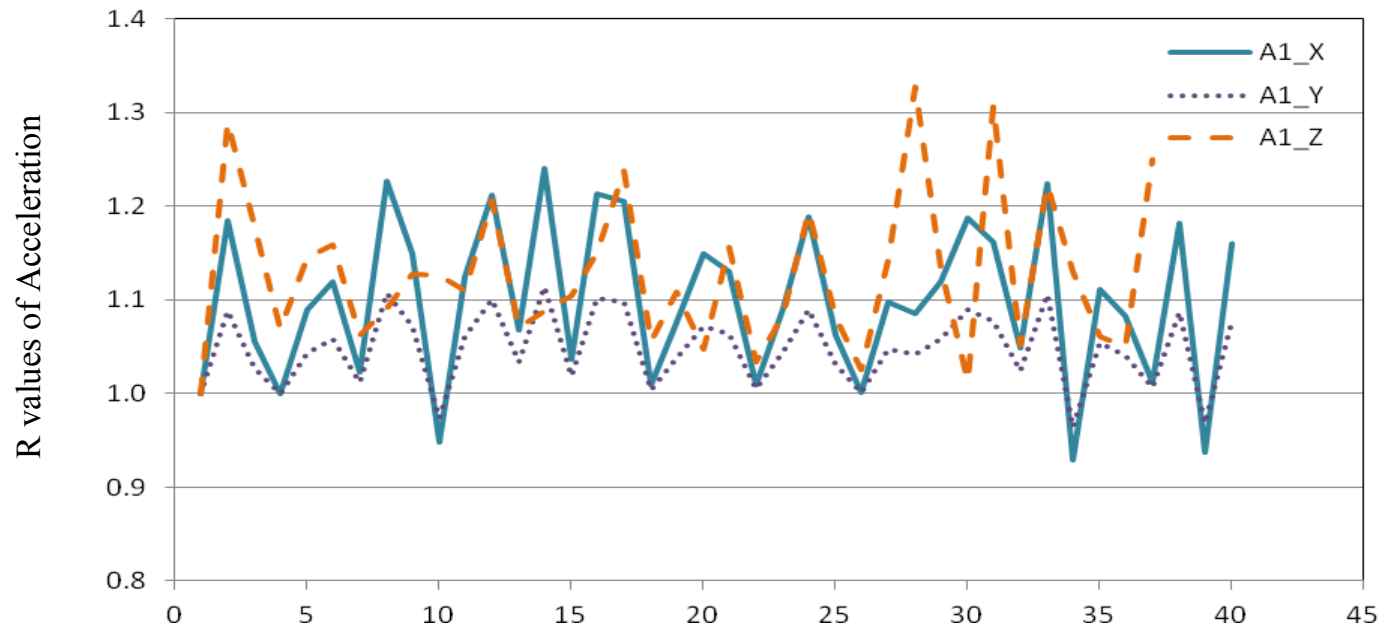

Sequence of data blocks

(b)

Figure 7: R-values of $\mathrm{x}, \mathrm{y}$ and $\mathrm{z}$ acceleration from Accelerometer $\mathrm{A} 1$ in live loaded conditions: (a) for 24 cases with 1 data block per 5 days; (b) for 37 cases with 1 data block per month 


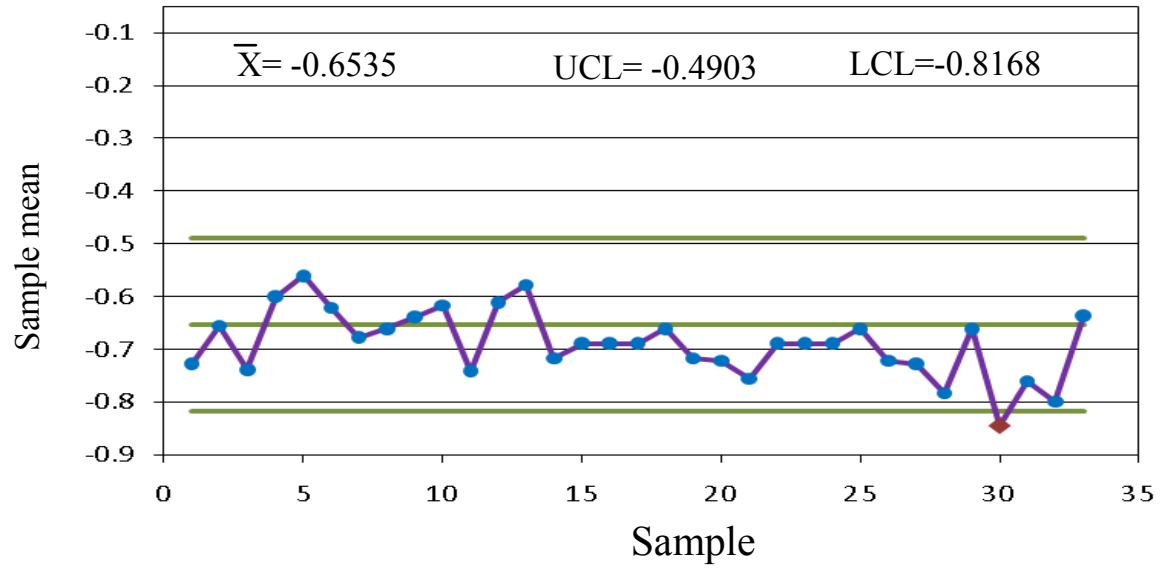

(a)

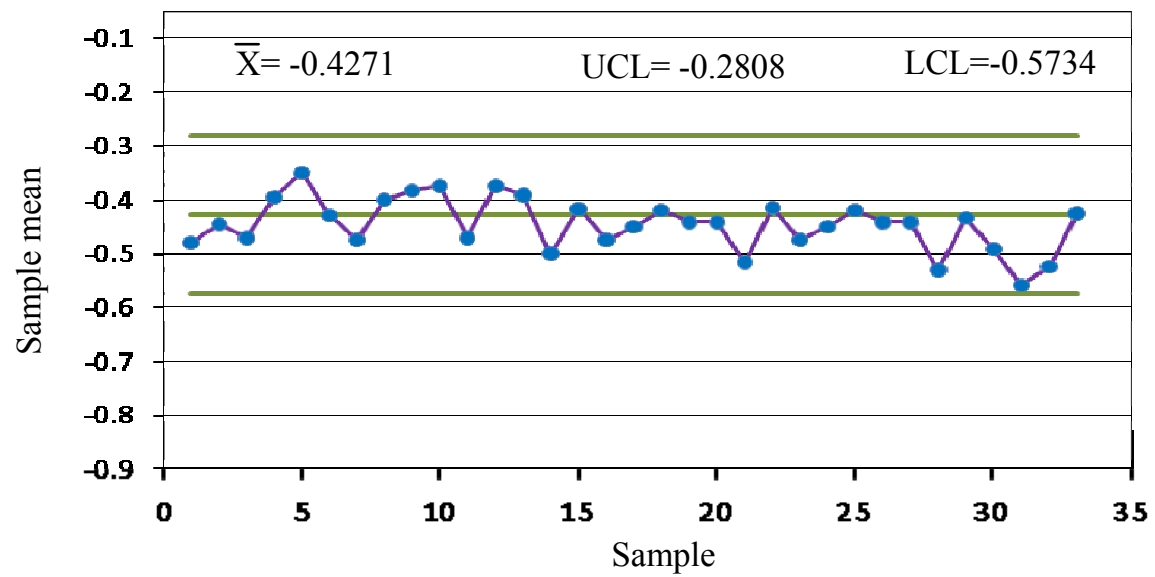

(b)

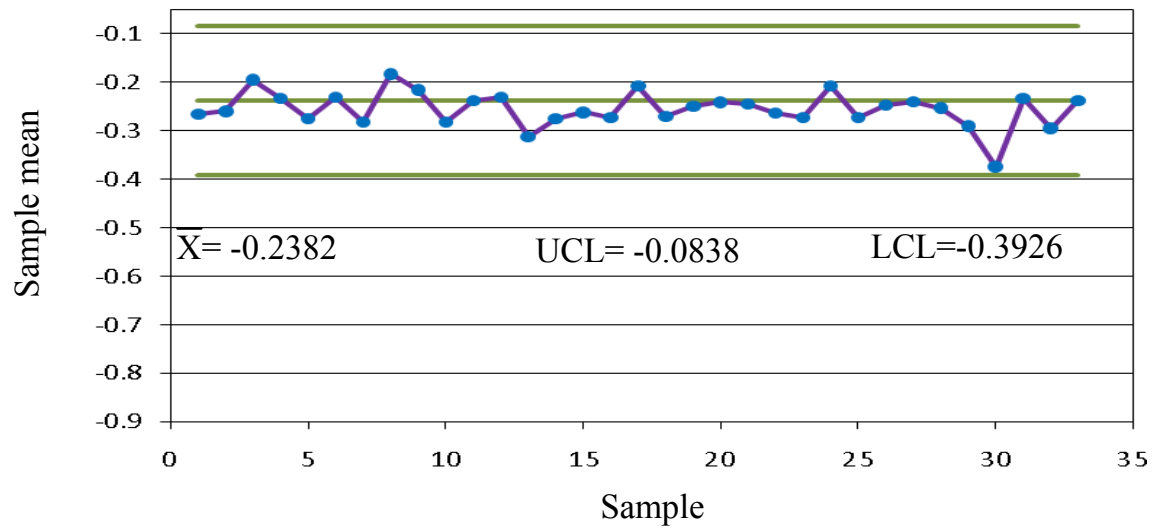

(c)

Figure 8: Outlier analysis of the AR Coefficients of strain readings from SG1 with Pool size of 132 and Subgroup size of 4: (a) first AR Coefficients; (b) first AR Coefficients; (c) third AR Coefficients 


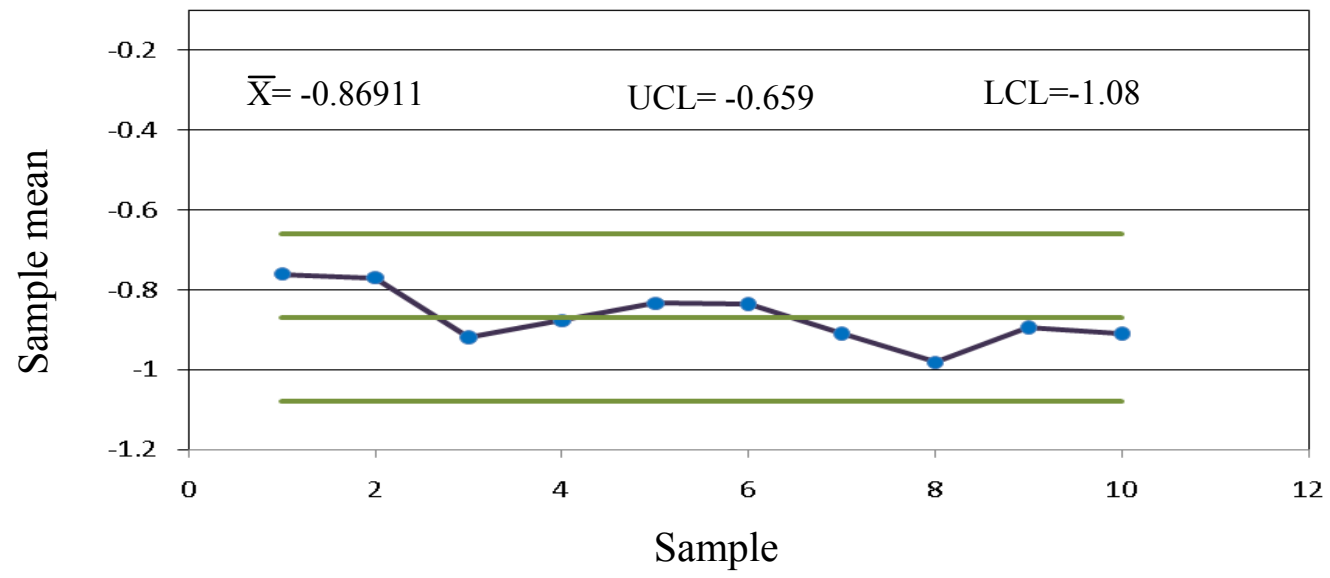

(a)

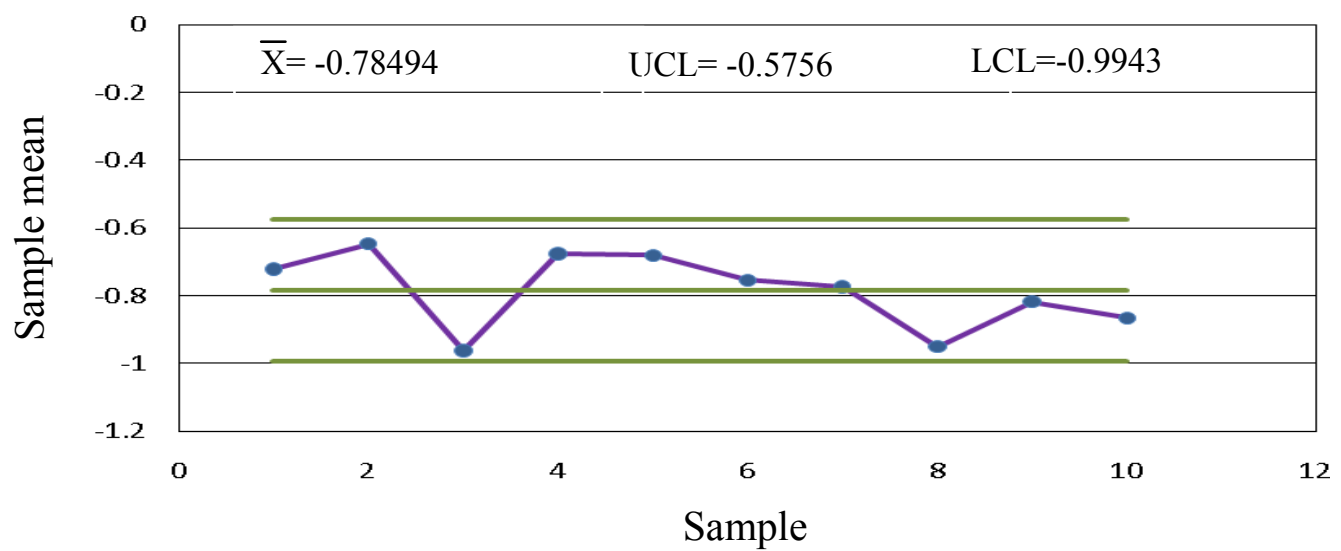

(b)

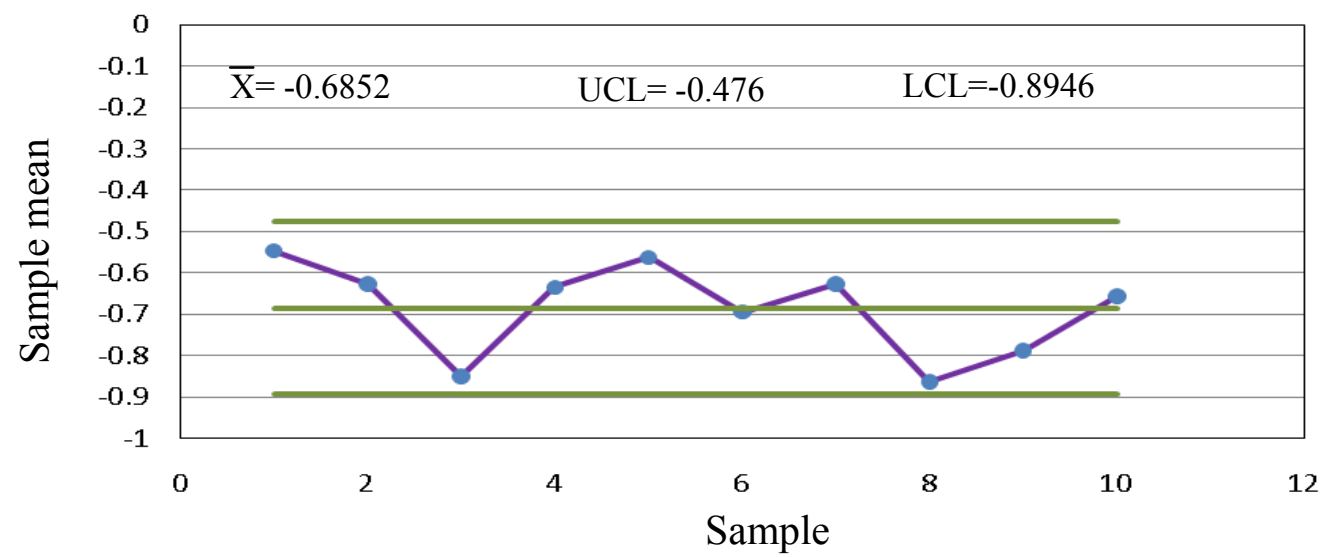

(c)

Figure 9: Outlier analysis of the AR Coefficients of strain readings from SG2 with Pool size of 40 and Subgroup size of 4: (a) first AR Coefficients; (b) first AR Coefficients; (c) third AR Coefficients 


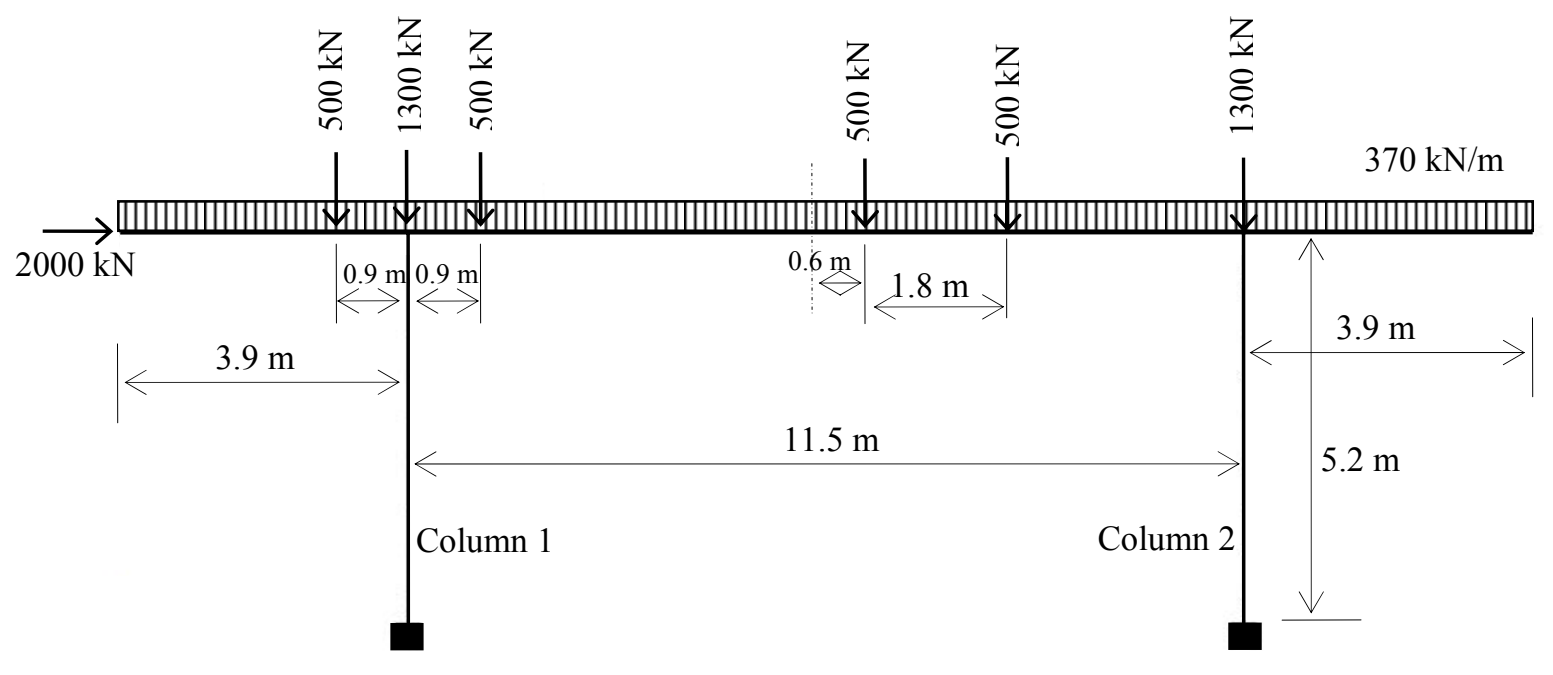

Figure 10: Two-dimensional model for Pier 2 of Portage Creek Bridge 


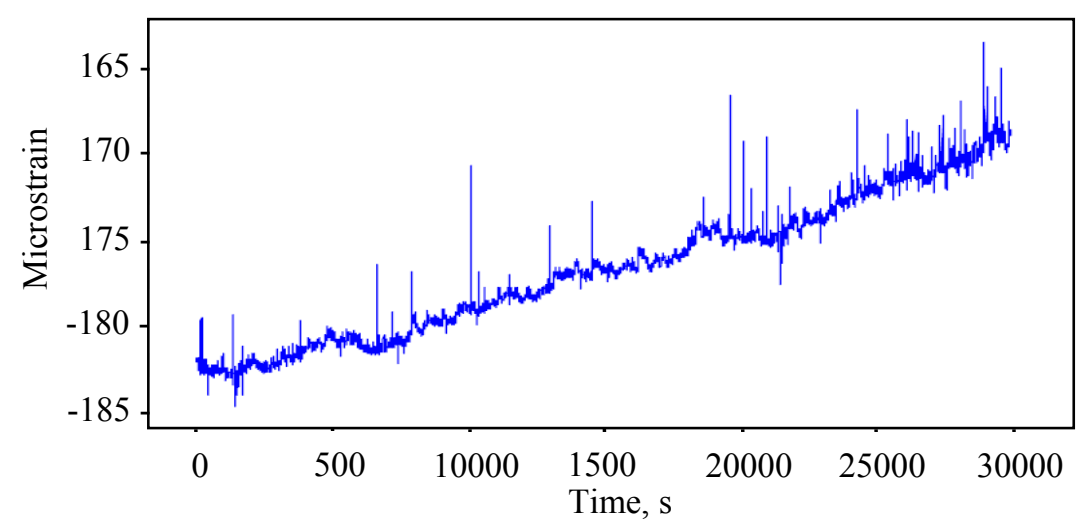

(a)

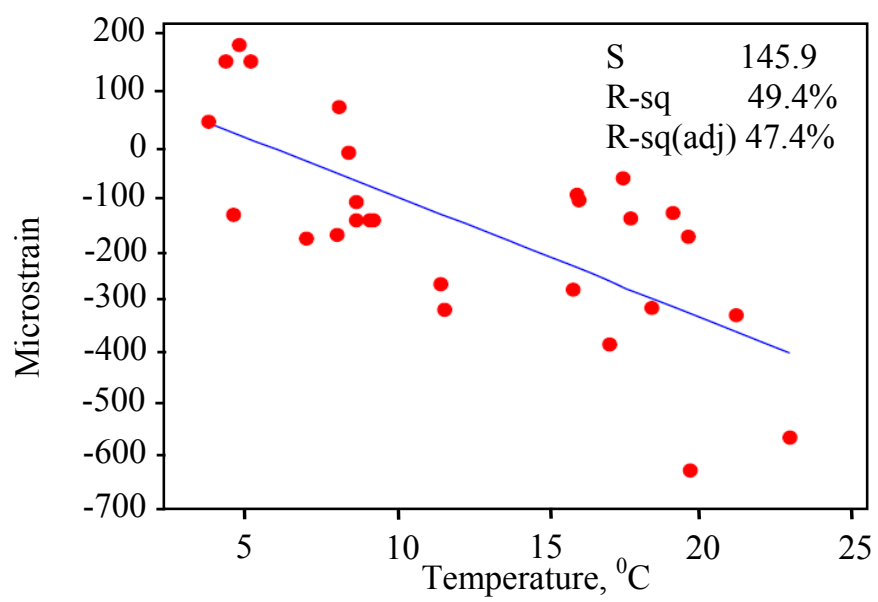

(b)

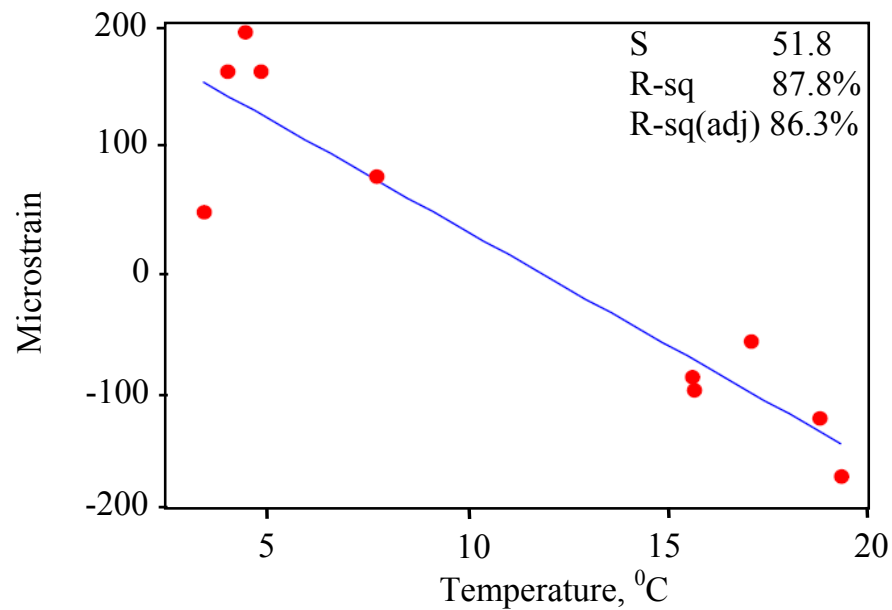

(c)

Figure 11: Temperature effect: (a) Strain values from SG1 at $1 \mathrm{~Hz}$ for 8 hours and 20 minutes at 0:0:0 time on 2006-03-01; (b) Temperature and Strain from SG1 for 27 monthly readings; (c) Temperature and Strain from SG1 for the first 10 monthly readings. 